\title{
Environmental monitoring based on data processing of Internet of Things
}

\author{
Alexander Ivanov ${ }^{1 *}$ and Alexander Platov ${ }^{1}$ \\ ${ }^{1}$ Nizhny Novgorod State University of Architecture and Civil Engineering, Nizhny Novgorod, Russia
}

\begin{abstract}
The concept of online monitoring of the urban environment is proposed. It is based on the online processing of hydrometeorological and traffic information received through the Internet of Things. The traditional approach of the Internet of things includes transfer and storage of huge arrays of measurements in digital form. This concept of online monitoring is primarily an analysis, evaluation of the results of processing information received from wireless networks. The concept was implemented at Nizhny Novgorod State University of Architecture and Civil Engineering in several services including Eco-routes, Quite-routes, in which the air pollution of the urban environment by vehicle emissions and the noise level from traffic flows are estimated in real time mode. The calculation is based on meteorological data and traffic flow velocity. The calculation and assessment of environment pollution is carried out at the request of the user via Internet. The concept includes micro weather and algal blooming monitoring of reservoirs and ponds. Developed services is the first to provide free short time health risk assessment for both decision makers and common internet users.
\end{abstract}

\section{Special environmental studies and loT procedures used}

Holistic approach of Internet of Things services was developed during last decade. It includes transfer and storage of huge arrays of measurements in digital form $[1,2]$. The next step is to use free Internet resources for detailed assessment and forecast. Currently, local meteorological information of the nearest weather station is available free of charge in real time via the Internet all over the world. This information includes temperature, pressure, humidity, solar radiation, wind speed and direction. In addition, in some countries, including Russia, it is possible to obtain online information on the speed of traffic flows in cities. This information is based on processing messages about the coordinates of GPS beacons of municipal transport moving along city streets.

The mentioned above information was used by the authors as the basis for the development of special online services. The specific assessment procedures require additional information, which is described below.

\subsection{Online monitoring of air pollution produced by traffic congestion}

In general case sources of air pollution are modelled by a set of point sources. Concentration of pollutants in accordance with the Gaussian model is as follows [3]:

$$
\begin{aligned}
& C=\frac{Q}{2 \pi U \sigma_{z} \sigma_{y}} \exp \left[-\frac{\left(y-y_{i}\right)^{2}}{2 \sigma_{y}^{2}}\right] \times \\
& \times\left\{\exp \left[-\frac{(z-h)^{2}}{2 \sigma_{z}^{2}}\right]+\exp \left[-\frac{(z+h)^{2}}{2 \sigma_{z}^{2}}\right]\right\}+F
\end{aligned}
$$

where: $C(x, y, z)$ is the concentration of a pollutant in the air, $\mathrm{mg} / \mathrm{m} 3 ; Q$ is the emission rate of the pollutant, $\mathrm{mg} / \mathrm{s} ; \sigma_{y}$ is the standard deviation of the Gaussian dispersion in the horizontal direction at $x, y-y_{i}, z ; \mathrm{m}$; $\sigma_{z}$ is the standard deviation of the Gaussian dispersion in the vertical direction at a point $(x, y, z) ; \mathrm{m} ; U$ is the wind speed, directed at $O x$ axis, $\mathrm{m} / \mathrm{s} ; F(x, y, z)$ is the background pollutant concentration, $\mathrm{mg} / \mathrm{m}^{3}, h$ is an elevation of road above a ground surface, $\mathrm{m} ; x, y_{i}, h$ are the emission source coordinates, $\mathrm{m}$.

Simplified model of sources is a set of linear sources. Both in general and simplified cases one should get online values $Q, U, \sigma_{y}$, and $\sigma_{z}$ for real time calculation of $C . U$ is available online directly via www.realmeteo.ru. $\sigma_{y}$ and $\sigma_{z}$ are characteristics of air stratification and distance from source of emission. $\sigma_{y}$ and $\sigma_{z}$ are calculated on the basis of source mapping and meteo data. $Q$ depends on traffic intensity $N_{a}$, traffic speed $V$ and composition of traffic flow (share of cars, trucks, buses etc.). Traffic speed $V$ is calculated on the basis of GPS beacons of municipal buses. Online

\footnotetext{
*Corresponding author: alexanderivanov52@yandex.ru
} 
flow intensity is calculated on the basis of preliminary long term investigation of traffic flow intensity and its dependence on traffic speed $V$ and traffic density. For detailed description please see paper of A. Ivanov and A. Platov [3].

Model of traffic flow intensity dependence on traffic speed and traffic composition during traffic congestion was used for online calculation of concentration of pollutants including nitrogen oxides of carbon oxide and hydrocarbons. The calculated concentration $C(x, y, z)$ was compared with in situ sampling and laboratory analysis of concentration. Conformity of online calculation and laboratory investigation of pollutant concentration is a basis for applying the online calculation model. The rationale of reliability of the calculation technique is presented in the second section of this article. Online calculations of $\mathrm{NO}_{\mathrm{x}}$ concentration for Nizhny Novgorod, Moscow and Yekaterinburg are available via http:/eco-routes.appspot.com.

\subsection{Online monitoring of noise pollution produced by traffic flow}

To monitor the noise level created by traffic flows, it is proposed to use a semi-empirical formula for calculating noise levels $L_{a e}$ based on online traffic speed $V$ and relatively stable traffic intensities $N_{a}$ calculated on the basis of special studies, the number of traffic lanes, and the share of heavy noisy vehicles $S_{h v}$ [4].

$$
L_{a e}=9.5 \lg N_{a}+12.6 \lg V+7 \lg \left(1+S_{h v}\right)+11.3 \text {; }
$$

where $L_{a e}$ is the calculated equivalent noise level at a height of $1.5 \mathrm{~m}$ at the distance of $7.5 \mathrm{~m}$ from the axis of the rightmost lane, dBA; $N_{a}$ is the estimated intensity of traffic, vehicles per hour; $V$ - speed of the traffic flow, km per hour; $S_{h v}$ - the share of trucks and buses, $\%$.

Traffic intensity $N_{a}$ is calculated on basis of preliminary research of traffic flow intensity dependence on traffic speed $V$ and traffic density, the same as for air pollution (1). Traffic speed $V$ is calculated on the basis of GPS beacons. The share of trucks and buses $S_{h v}$ is considered constant and based on long term research of traffic flow in the different zones of the city.

The calculated noise level was compared with in situ noise measurements for several places and dozens of points. Online calculation of noise level produced by traffic flow is available via http:/quiteroutes.appspot.com. The rationale of reliability of the calculation technique is presented in the second section of the paper.

\subsection{Online monitoring of local micro weather parameters}

Monitoring of micro-weather characteristics of temperature and wind speed is important for assessing the favourable conditions of constantly changing meteorological conditions of the urban environment. The most important parameters are the effective perceived temperature, local wind speed, local humidity, solar radiation level and pressure.

An important effect is the wind-cold effect of influencing the perceived temperature $T_{W C}$ in the winter season.

$$
\begin{aligned}
& T_{W C}=13.12+0.6215 T_{c}-11.37 U_{10}^{0.16}+ \\
& +0.3965 T_{a} U_{10}^{0.16} ;
\end{aligned}
$$

Here $T_{a}$ is a local air temperature, ${ }^{\circ} \mathrm{C}, U_{10}$ is a standard meteorological data based on measurements of wind speed at a height of $10 \mathrm{~m}, \mathrm{~m} / \mathrm{s} ; U$ - wind speed at a height of $1.5 \mathrm{~m} ; \mathrm{U}_{10}=1,5 \mathrm{U}$.

Local measurements of $T_{a}$ and $U$ are used for local perceived temperature $T_{W C}$ calculations. For online rough estimation and forecast wind speed $U$ model of Myagkov was used [5]:

$$
U=K U_{m s}(1-\beta)+\beta U_{m s}
$$

Here $U_{m s}$ is wind speed measured at adjacent meteorological station available free by Internet. $\beta$ is share of area covered by street canyons. $K$ is coefficient of wind speed attenuation by green zones and low buildings.

$$
K=(1+\sqrt{\varepsilon})(1+\varphi)+\varphi
$$

Here $\varepsilon$ is share of area covered by high building; $\varphi$ is share of flat area covered by lakes, meadows and fields.

Similar approach for online perceived temperature calculation during solar shock and heat shock in summer season is based on Myagkov simplified formula (4).

The possibility of applying those approaches still remains uncertain and requires additional research as it will be described at the second part of the paper.

\subsection{Online monitoring of algal blooming in reservoirs, lakes and ponds}

Algal blooming is seen as blue\&green impurity affecting transparency and producing turbidity. This effect can easily be measured by Secchi depth $d$ of the upper layer of the lake-type water body, see Bradford-Mayero model [6]. A modified formula is obtained that relates the concentration of chlorophyll $\mathrm{C}$ with Secchi depth $\mathrm{d}$ and the light attenuation coefficient in the surface layer $k_{s 0}$ obtained under winter conditions when the biotic component of this reservoir is negligible compared to the abiotic

$$
C_{c h l}=\left(\frac{7.7}{d}-4 k_{s 0}\right)^{1.47} ;
$$

Here $k_{s 0}=0.64$ for the Gorkovsky reservoir; Here $C_{c h l}$ is concentration of chlorophyll in the surface layer.

Forecast of the temperature of the upper layer gives way to online forecast of the algal blooming because following to fig. 1 online calculated Secchi depth $d$ is

$$
d=-5.9573 T_{a}+297.84
$$

Using formula (6) one can roughly calculate relevant concentration of chlorophyll and compare calculated 
value with dangerous level recommended by World Health Organization.

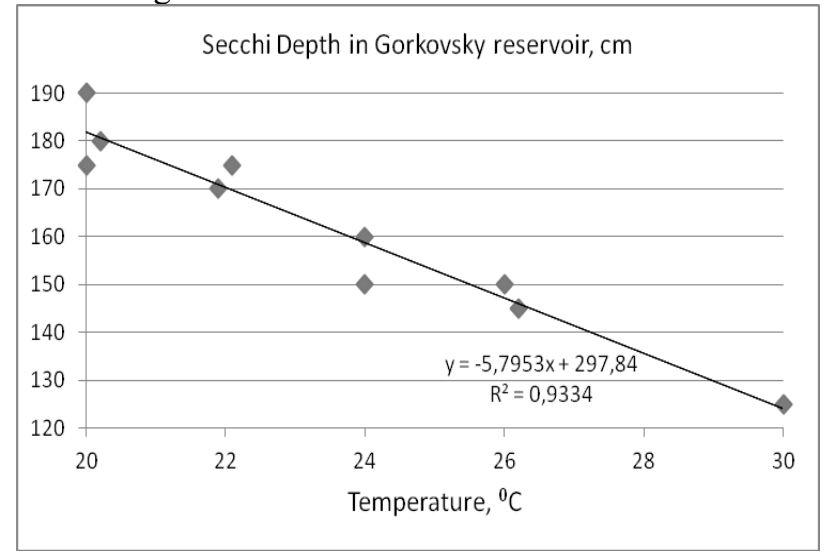

Fig. 1 Dependence of Secchi depth $d$ on air temperature $T_{a}$ for the Gorkovsky reservoir.

The open question is limits of this simplified model. At least extreme weather events are crucial for the model.

\section{Verification of the models}

Online calculation of air pollution by traffic congestion was compared with laboratory analysis $\mathrm{NO}_{\mathrm{x}}$ concentration at air samples. Research was held on Komsomolskaya square located on flan open area on the left bank of the Oka river in Nizhny Novgorod. Comparison indicated good agreement between observation and calculation results concerning average value, as it is seen from fig.2. Relatively low $\mathrm{R}^{2}$ may be explained by small distance from vehicles as discrete sources of pollution.

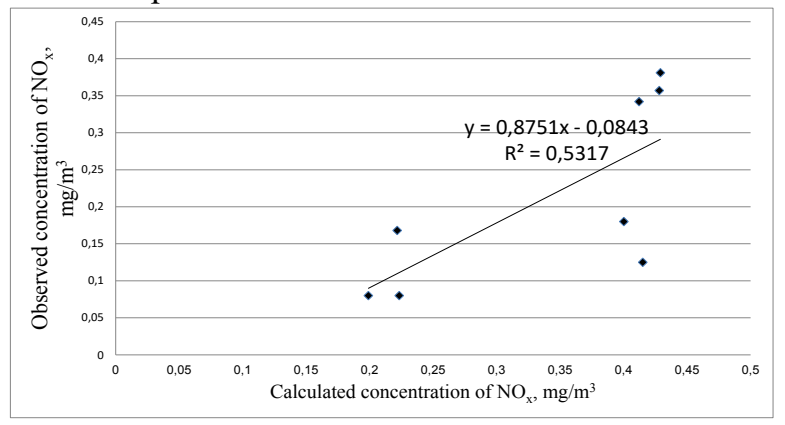

Fig. 2. Comparison of online calculated and observed concentrations of $\mathrm{NO}_{\mathrm{x}}$ for area adjacent to the road.

Comparison of online calculated and measured noise level indicated good matching of noise level growth with increasing flow intensity, see fig. 3. Systematic discrepancy between the measured and online calculated mean level is a matter of further investigation because the calculation formula (2) used in this work was obtained for the noise generated by traffic in Moscow. We need special relevant investigation for the noise generated in Nizhny Novgorod where flow density and number of lanes is less than in Moscow.

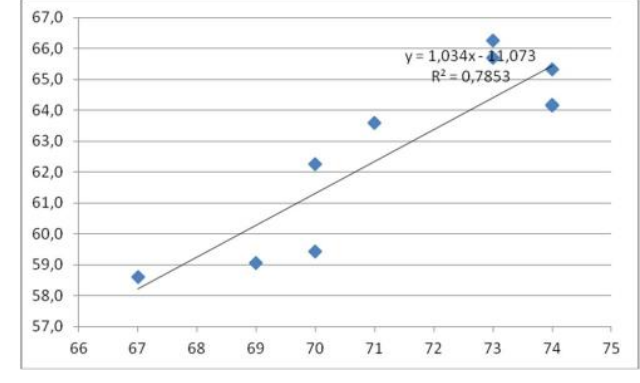

Fig. 3. Comparison of online calculated and observed noise level for area adjacent to the road 7,5 $\mathrm{m}$ far from road lane.

Local weather research was held using air anemometer and professional Internet meteorological station. The data were compared with official monitoring data available via Internet. Comparison showed good agreement between local data for open space located in city centre and data obtained by meteorological station located near airport, see fig. 4. We consider this area good for online calculation of modulated by buildings and green zones in accordance with (4) and (5) [5].

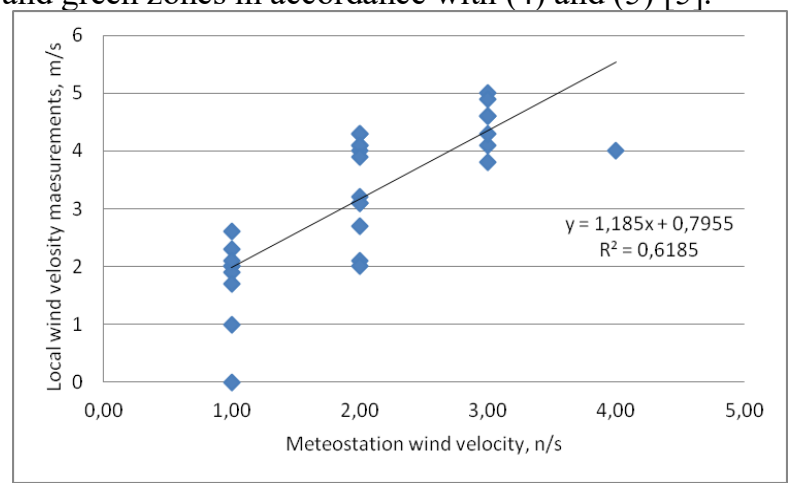

Fig. 4. Comparison of wind velocity measured by federal monitoring meteorological station and by anemometer located at open boulevard area

The research indicated unique weather regime at riverside area. Wind speed and wind direction are influences significantly by water surface temperature. In particular, water temperature in the river depends on overheated discharges. Relevant air overheating produces local pressure gradient above water surface. Fig. 5 indicates very poor agreement between online meteorological data and local measurements. It makes senseless to use simplified model of wind speed modulation by street canyons and green zones [5].

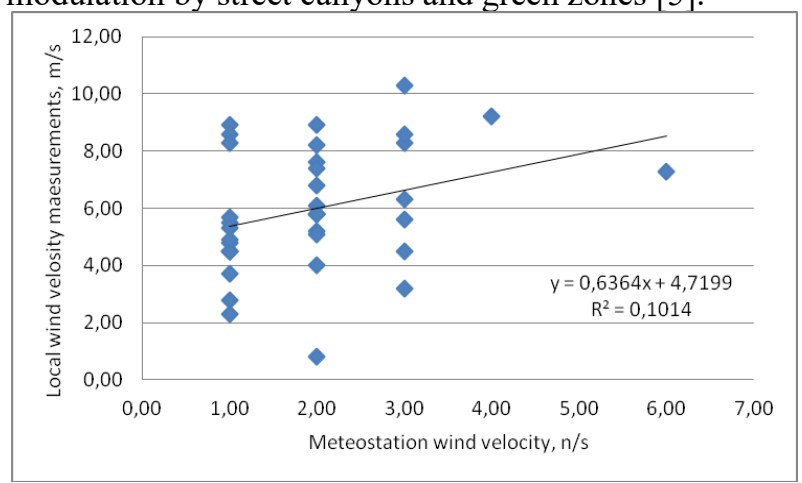

Fig. 5. Comparison of wind velocity measured by federal monitoring meteorological station and by anemometer located at floodplain area. 
Local temperature and wind speed were used to assess wind cold effect for open public area during winter. Every day measurements were held during the coldest period of the winter that is during last decade of January and first half of February. Registered temperature and calculated perceived temperature are shown on fig. 6. During the period the registered temperature never was lower than $-15^{\circ} \mathrm{C}$. During 5 days perceived local temperature was lower than $-25^{\circ} \mathrm{C}$.

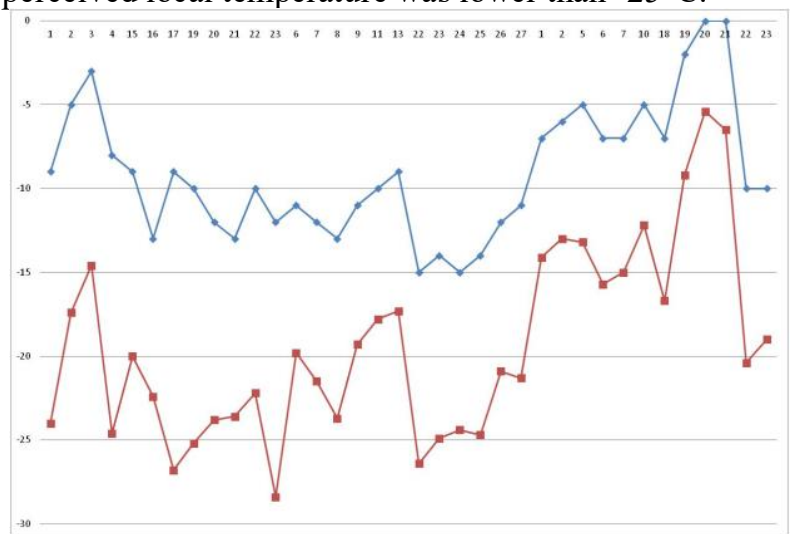

Fig. 6. Wind cold effect registered during 23 day measurements for a local area. The upper (blue colour) line is local temperature record and the lower (red colour) line is calculated perceived temperature for open local area.

There is no free online data of local water bodies monitoring. It makes a reason for development of relevant forecast model for Gorkovsky reservoir on the Volga river. The model is based on meteorological data. The result of modelling is shown on fig. 7 [7].

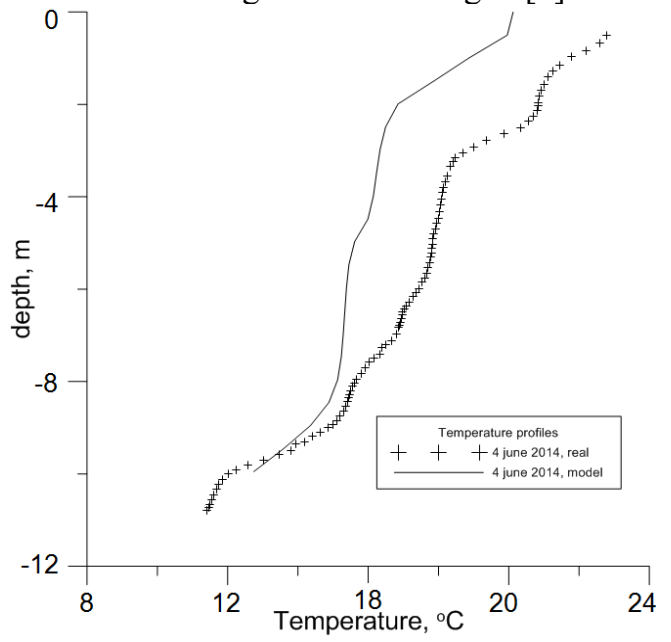

Fig. 7 Comparison of actual stratification and calculations using the LAKE computing package performed by A. Ivanov et al. [7].

The above model is a basis for forecast of chlorophyll $\mathrm{C}$ concentration using formula (6). The next step will be modelling of phytoplankton distribution with depth. Example of biomass concentration research is shown on fig.8. The research included sampling and concentration identification using extraction and measuring size and number of algae [8].

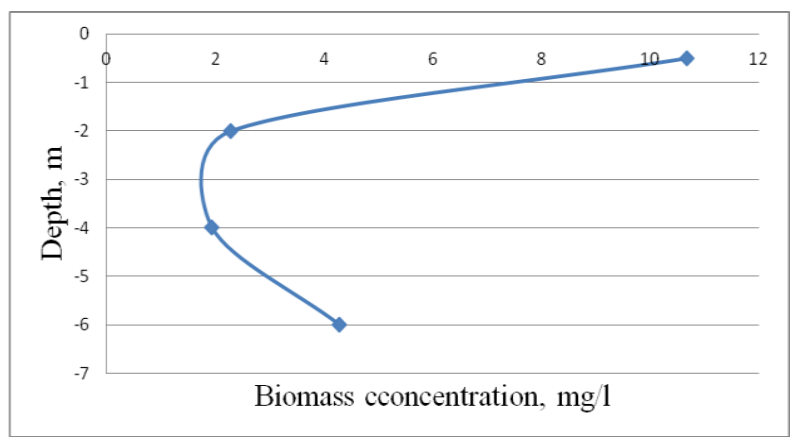

Fig. 8. Phytoplankton biomass concentration at different depth.

\section{Discussion and conclusion}

The paper presented the concept of local environmental monitoring based on the organization of regular measurements and performing online calculations using free Internet resources. It included online calculation of air pollution produced by traffic congestion, online calculation of noise pollution produced by traffic flow, online calculation of local weather effects and online calculation of algal blooming of urban ponds, reservoirs and lakes. Relevant online services are available free of charge via http:/quite-routes.appspot.com and http:/ecoroutes.appspot.com.

This type of monitoring is considered as a tool for local liveable projects to improve environment, safety and resilience.

Developed services provide both short time and long time health risk assessment for decision makers and common internet users.

The work was supported by Russian Science Foundation project 15-17-20009.

\section{References}

1. J. Gubbia, R. Buyyab, S. Marusic, M. Palaniswami. Internet of Things (IoT): A vision, architectural elements, and future directions /Future Generation Computer Systems 29, 1645-1660 (2013)

2. K. Ashton, How to Fly a Horse: The Secret History of Creation, Invention, and Discovery Hardcover January 20, 2015.

3. A. Ivanov, A. Platov. International Multidisciplinary Scientific Geoconference SGEM 2019. Conference proceedings V.19, Informatics, Geoinformatics and Remote Sensing Issue 2.1 p.1099-1106 (2019)

4. I.E. Tsukernikov. Sbornik dokladov IV Vserossiyskoy nauchno-prakticheskoy konferentsii s mezhdunarodnym uchastiyem (in Russian). S. Peterburg, Russia, p.36-51 (2013).

5. M.S. Myagkov, Yu.D. Gubernskiy, L.I. Konova, V.K. Litsiyevich Gorod, arkhitektura, chelovek I klimat (in Russian). Moskva, Arkhitektura, 344 p. (2007).

6. H.L.Bradford, D.J.Maiero. Procs.ASCE., J.Env.Eng.Div., 104(EE5), pp.981-996 (1978). 
7. A. Ivanov., Y. Troitskaya, D. Sergeev, G.Baydakov, D. Gladskikh 17th International Multidisciplinary Scientific GeoConference SGEM 2017 Extended session p. 259-266 (2017).

8. A. Ivanov, S. Guseinova, I. Kraev, D. Malyshev. International Multidisciplinary Scientific Geoconference SGEM 2019. Conference proceedings V.19, Water Resources, Forests, Marine and Ocean Ecosystems Issue 3.1 p.473 480 (2019). 